\title{
A Barca do Inferno: o tempo de Gil Vicente e o nosso tempo
}

José Augusto Cardoso Bernardes ${ }^{1}$

Enviado em: 27/09/2018

Aceito em: 02/02/2019

RESUMO: Existem sinais seguros de que o Auto da Barca do Inferno teve grande êxito junto do público ao qual se destinou. Ao longo dos séculos, essa peça de Gil Vicente continuou depois a gozar de especial acolhimento. Assim o atestam as frequentes representações teatrais, uma dinâmica editorial invulgar e ainda a presença assídua que vem mantendo nos programas escolares. $\mathrm{O}$ presente estudo procura cumprir dois objetivos: identificar os motivos que podem estar na base desse sucesso e faze $\mathrm{r}$ um levantamento de alguns dos pontos mais obscuros que subsistem na interpretação do texto para o leitor comum.

Palavras-chave: Teatro português quinhentista; Filosofia medieval; Metafísica; Existência.

ABSTRACT: There are strong signs of the imediate success of the Auto da Barca do Inferno, along side it's target public. As time went on, this particular Gil Vicente's Play enjoyed of a continous warm reception: whether we look at the number of performs done, print editions or it's regular presence in the school programs. This study is trying to deliver two main goals: to identify the motives behind the success of this theatre play; and also to pinpoint some parts that remain misunderstood and obscure for the common lector, concerning the interpretation of the text.

Keywords: 16th century Portuguese theater; Medieval philosophy; Metaphysics; Existence.

\section{Um texto especial}

O Auto da Barca do Inferno é, sem dúvida, um dos textos mais conhecidos do teatro português. O primeiro sinal do seu êxito vem do próprio século XVI e traduz-se no facto de ter sido editado isoladamente (em 1519), muito antes de aparecer na Compilação que, como é sabido, apenas veio a lume em 1562, um quarto de século após a morte do autor. O seu impacto é ainda certificado pelo elevado número de edições de que foi objeto ao longo dos séculos, o que lhe confere um lugar destacado no âmbito de todas as produções vicentinas ${ }^{2}$.

Um dos motivos que explicam um sucesso tão grande e continuado está decerto relacionado com o facto de se tratar de uma peça centrada no tema da justiça post-mortem, uma das zonas de curiosidade mais constantes na história humana. Não esqueçamos que no tempo de Gil Vicente (e muito para além dele) a eternidade constituía uma certeza, suscitando o interesse comprometido e indagativo da generalidade das pessoas.

Um segundo motivo que pode explicar o impacto da peça resulta talvez da própria

\footnotetext{
${ }^{1}$ Professor Catedrático na Faculdade de Letras de Coimbra e membro integrado do Centro de Literatura Portuguesa. Para além de ter publicado estudos sobre autores canónicos da Literatura Portuguesa, com destaque para Gil Vicente e Luís de Camões, vem-se dedicando aos problemas da investigação e do ensino das Humanidades em contexto nacional e internacional.

${ }^{2} \mathrm{O}$ estudo mais recente e mais completo sobre a dinâmica editorial da obra de Gil Vicente ao longo dos séculos foi recentemente publicado por José Camões: "A fortuna editorial da obra de Gil Vicente", in Compêndio de Gil Vicente (coordenação de José Augusto Cardoso Bernardes e José Camões).
} 
forma como o julgamento dos mortos é levado a cabo. De facto, ao contrário do que pode parecer numa primeira aproximação, na Barca do Inferno o Além não é visto como um prolongamento da vida terrena. Pelo contrário: o tempo da Morte caracteriza-se por diferenças substantivas que podem ter impressionado os espetadores de diferentes épocas. Se virmos bem, na Barca do Inferno só depois da morte prevalecem a "justiça plena" e a "verdade clara". Como se vê em várias personagens que tentam evitar a condenação, as palavras e as atitudes que regem o funcionamento do mundo nada podem já contra essa nova dimensão da Justiça e da Verdade.

O mundo dos vivos parece assim habitado por espectros que só depois da morte se transformam em pessoas. Afinal, antecipando o teatro de Calderón, já em Gil Vicente se pode dizer que os vivos são sombras dos mortos e não o contrário.

Por último, o auto impressiona por contemplar as três soluções previstas na escatologia católica. Nele surgem nomeadamente os pecadores, os justos e os perfeitos, seguindo a conhecida diferenciação de S. Gregório Magno (século VI), incorporada na generalidade dos tratados de Escatologia ${ }^{3}$.

Em função de todos estes fatores potencialmente aliciantes, não admira que o auto tenha também inspirado um vasto caudal de estudos críticos. É abundante e minuciosa a bibliografia sobre as "fontes" da peça, por exemplo. Onde pode Gil Vicente ter encontrado inspiração para o julgamento a que submete as suas personagens? Qual a importância das "fontes" literárias ou dramatúrgicas? Quanto pesa no auto um substrato figurativo concreto como a dança macabra? 4

Num plano mais geral, muito se escreveu também sobre o contexto histórico-cultural que envolve a figura de Gil Vicente. A este respeito pode perguntar-se, por exemplo: qual o tipo de relações que o dramaturgo mantinha com os dois monarcas a quem serviu? Até que ponto poderia ir o artista na sátira que dirige à corte e aos costumes do seu tempo? Será a Barca do Inferno um friso social do século XVI português?

São já abundantes e sólidos os resultados apurados neste e noutros domínios da erudição. Mas falamos da investigação académica, aquela que vai alimentando uma determinada subárea de estudo mas dificilmente chega ao leitor comum. Não haverá, provavelmente, muita gente interessada em saber se, na conceção desta peça, Gil Vicente se inspirou ou não na Dança da Morte (uma das prováveis fontes iconográficas de que falávamos acima) ou para escrever as duas que se seguiram imediatamente, tendo por temas o Purgatório (1518) e o Paraíso (1519).

É ainda menos provável que o espectador (ou o leitor) cultive uma curiosidade mais detalhada, a que dão resposta as notas de roda-pé de algumas edições vicentinas: quem era afinal um tal Garcia Moniz que o Enforcado menciona, dizendo que ele lhe garantira que, depois de cumprir o castigo ditado pela justiça dos homens, ficaria isento de penas na outra vida? Por que razão terá Gil Vicente escolhido um frade dominicano (e não de outra ordem religiosa) para representar a mundanidade dos clérigos? Por que motivo neste auto (como em muitos outros) a crítica vicentina à justiça se revela tão forte e insistente? Como se explica a informação constante da Didascália, segundo a qual a peça foi representada nos aposentos de uma rainha doente e prestes a falecer? Trata-se de uma circunstância fortuita

\footnotetext{
${ }^{3}$ Para uma pespetiva analítica e histórica da Escatologia cristã veja-se Tamayo-Acosta (Juan-José). O mesmo tema encontra-se tratado de forma mais profunda e abrangente na Primeira e na Segunda Partes do The Oxford Handbook of Eschatology (Edited by Jerrry L. Walls).

${ }^{4}$ Em ocasião anterior, tive já oportunidade de me ocupar deste mesmo assunto: “As Barcas de Gil Vicente: artes moriendi e horizonte escatológico na corte de D. Manuel".
} 
ou de um dado contextual que condiciona o sentido geral da peça? 5

Em Portugal, quem hoje assiste à representação do auto conhece-o pelo facto de ele ser estudado na Escola. O aluno português tem notícia geral sobre o autor e a obra. Sabe que a Barca do Inferno faz parte de um conjunto de cerca de meia centena de peças, e que esse mesmo conjunto é assinalado por uma acentuada heterogenei-

dade. Reconhece-se facilmente que o autor das Barcas é o mesmo de Alma; mas, para alguém menos familiarizado com a diversidade dos géneros do teatro medieval, pode porse em dúvida que se trate do mesmo dramaturgo que escreveu peças tão diferentes no tema e na estrutura como o Auto da India, a Comédia de Rubena ou o Pranto de Maria Parda. Costuma causar surpresa nomeadamente que o autor tenha escrito e feito representar cerca de 50 peças, com uma regularidade impressionante, ao longo de 35 anos, coincidindo com a quase totalidade do reinado de D. Manuel e com parte do reinado de seu filho, D. João III.

A Barca do Inferno é seguramente a peça que figura no cânone escolar, de forma mais regular. Atualmente, em Portugal, estuda-se no $9^{\circ}$ ano, quando o aluno ronda os 14 anos de idade, ao longo de um mês e meio, quase sempre entre finais de Outubro e o Natal. Logo depois de uma introdução biográfica e histórico-cultural e de uma descrição panorâmica da estrutura, o aluno aproxima-se de cada uma das personagens para the perceber o significado social e moral. Não é forçoso que o professor se detenha em todas as figuras com a mesma minúcia. Algumas impõem-se mais do que outras, ou porque parecem portadores de uma carga teatral mais forte ou porque se apresentam mais próximas da realidade social e moral dos nossos dias ${ }^{6}$.

Tocados por situações de analogia que envolvem o tráfico e a exploração de pessoas (de que, infelizmente, continuamos a ter notícia), todos reparam na alcoviteira, retendo o papel que desempenha no tráfico que então se fazia, nas habilidades de sedução que exerceu em vida e persiste em praticar depois da morte, quando tenta convencer o Anjo a ignorar os seus pecados e a acolhê-la na sua barca. Do mesmo modo, os alunos reparam no judeu, estranhando quase sempre que a sua condenação se deva apenas a um "pecado de religião". Costumam inclusivamente notar que se trata de um condenado especial: viaja para o inferno como a grande maioria dos que se submetem a julgamento; mas, como se isso não bastasse, viaja do lado de fora da embarcação, parecendo assim ser alvo de um castigo reforçado. Sem recorrer a informação histórico-cultural, os professores que tanto enaltecem o talento de Gil Vicente experimentam depois alguma dificuldade em explicar que esse dramaturgo genial tenha consentido numa condenação que hoje seria inaceitável. Por fim, quando confrontados com o pecado do frade, os adolescentes reconhecem facilmente muitos pecados modernos atribuíveis a clérigos ou a outras pessoas que facilmente quebram regras e votos para se entregar aos prazeres, esquecendo compromissos e obrigações.

Acima de qualquer outra personagem, porém, os alunos costumam simpatizar com o parvo Joane. Com ele, com as suas atitudes e palavras de rebeldia obscena se riram já sucessivas gerações de alunos e professores.

Acredita-se até que seja muito por causa dessa figura estranha mas cativante que Gil Vicente (e este auto em particular) mantém, desde há muito, uma posição estável nos programas escolares ${ }^{7}$. Afinal, a inesperada irreverência de palavras que caracteriza a

\footnotetext{
${ }^{5}$ A este propósito, deve notar-se que na versão impressa de 1519, não consta esta indicação de circunstância.

${ }^{6}$ No já citado Compêndio de Gil Vicente, figura um muito esclarecedor estudo de Amélia Correia sobre este mesmo assunto: "Gil Vicente no cânone escolar. O(s) texto(s) e a(s) leituras".

7Para além deste fator relacionado com o impacto dessa personagem especial que é o Parvo Joane, existe um outro que pode explicar o favor de que o auto vem gozando na Escola: refiro-me à ideia de que nele se retrata o vasto
} 
personagem também serve para provar que, mesmo há quinhentos anos, quando a sociedade era muitíssimo mais repressiva do que hoje, os escritores (e os artistas em geral) criavam alternativas ao discurso alinhado, correto e respeitador que normalmente associamos ao Poder. E não se pode deixar de simpatizar com Gil Vicente quando ele reserva um lugar no Paraíso a esses desalinhados. Sabemos que o destino

final do Parvo será bom. Pode até estranhar-se que ele não entre imediatamente na embarcação do Anjo. O Parvo tem de aguardar enquanto os cavaleiros, que chegam no final da peça, obtêm entrada imediata na barca do Céu. Existe uma tónica comum: as personagens boas (Joane e os cavaleiros) caracterizam-se pelo seu desapego em relação ao Ter e ao Poder.

Em lugar de se terem deixado seduzir pelos bens materiais, os cavaleiros entregaramse a uma causa de natureza espiritual, pagando essa entrega com a própria vida. Podemos hoje colocar em causa o sentido e os fundamentos dessa dádiva. O que conta na peça, contudo, é que se trata de um compromisso de renúncia, em tudo oposto ao mundo de enganos e prazeres em que escolheram viver todos os condenados.

A mesma atitude de renúncia é identificável no Parvo. A este respeito, a sua resposta identificadora perante o Anjo não deixa margem para dúvidas:

Anjo - Quem és tu?

Parvo - Nam sou ninguém ${ }^{8}$. (p. 225)

Do ponto de vista da lógica da Salvação, depois do "desprezo do mundo" falta ao Parvo o compromisso explícito com a causa da Fé. Embora indiciado desde logo, esse compromisso surge apenas, de forma plena, com os cavaleiros.

É da correlação entre estas três soluções que resulta a Lição da moralidade vicentina.

\section{Dificuldades de leitura}

Ver em palco uma peça que se conhece não é a mesma coisa do que assistir a uma outra sobre a qual não temos informação. Neste caso concreto, todos sabem antecipadamente o que vai acontecer. É certo que o encenador conserva sempre uma boa margem de liberdade. Ainda assim, seria surpreendente que a vontade do dramaturgo fosse subvertida, a ponto de se colocar no Inferno quem Gil Vicente encaminhou para o Paraíso. Convém lembrar, a este propósito, que estamos perante uma moralidade, género teatral que, entre outros traços, se distingue pelo facto de nele ser bem visível a diferença entre o Bem e o Mal. Isso significa, na prática, que as personagens surgem caracterizadas com nitidez definitiva: de um lado situam-se aquelas que, tendo pecado gravemente, não podem ser salvas e, do outro, aquelas que conquistaram o Paraíso através de uma conduta virtuosa.

Ainda assim, mesmo sem alterações drásticas no domínio do conteúdo, sobram vários elementos de expetativa que podem ser explorados pelo encenador, pelo ator ou mesmo pelo aderecista.

Não sabemos exactamente como eram os Anjos e os Demónios que Gil Vicente apresentou à Corte em 1516 ou 17. Apenas podemos imaginar estereótipos através da

espetro social da sociedade portuguesa de Quinhentos. Independentemente das reservas que possam colocar-se à autenticidade desse "retrato", a possibilidade de através de uma só peça se poder proporcionar aos alunos um contacto com esse tempo mítico de Portugal tem tido decerto um forte peso nas escolhas do texto.

${ }^{8}$ A resposta que surge na folha volante de 1519 ("Samicas alguém”) é literalmente diferente, embora sem se afastar do sentido de humildade e de contraposição relativamente a todos os condenados. 
iconografia9. É certo que se tratava de figuras incomunicáveis entre si. Sabemos ainda (e é importante lembrá-lo enquanto assistimos à peça) que, ao contrário do que hoje acontece, Anjos e Demónios não eram simples entidades míticas. Bem pelo contrário: a sua existência era tida por certa.

Hoje, que essa crença deixou de ser consensual, subsiste a curiosidade em saber como vão surgir em palco os representantes do Paraíso e do Inferno. Em princípio, deverá haver neles uma margem de convenção que possibilite o reconhecimento. Mas fica em aberto uma componente indefinida, que dependerá da criatividade do encenador, contando inclusivamente com a mudança e a flexibilidade que entretanto se operaram na percepção do Bem e do Mal.

Um dos desafios mais interessantes para quem hoje encena a Barca do Inferno ou qualquer outra moralidade vicentina reside, de facto, na composição das figuras do Anjo e do Diabo, o mesmo é dizer da representação da virtude e do pecado. Tanto mais que, para além de traços constantes, o dramaturgo introduz notas de singularidade, que variam de peça para peça: o Diabo e o Anjo das Barcas não coincidem, desde logo, com as figuras do mesmo nome que surgem no Auto da Alma, apesar de este ter sido representado em $1518^{10}$, poucos meses depois da Barca do Inferno e no mesmo ano de Purgatório. Neste caso, tanto o Anjo Custódio como o Diabo do Auto da Alma são figuras atuantes e empenhadas em influenciar as escolhas da figura de mulher que atravessa a vida e que cede alternadamente a um e a outro. Os primeiros, os das Barcas limitam-se a certificar os motivos que levam as personagens ao batel do Paraíso ou ao batel da Perdição. Nada podem fazer para evitar esse destino pré-definido: tanto das muitas figuras que são objecto de condenação como das poucas que alcançam a salvação.

Alguns dos dilemas que se colocam ao encenador e ao ator da Barca do Inferno resultam da estranheza que o espectador do século XXI experimenta relativamente à dicção, ao vocabulário, aos movimentos e aos ritmos que andam associados às figuras do século XVI. Como pode conjugar-se a identidade epocal das figuras com a necessidade de as tornar reconhecíveis aos olhos do espectador de hoje?

O mesmo sucede com o estudo do auto, nas aulas de Português. À luz da tolerância religiosa que hoje felizmente não se coloca em causa, os alunos têm dificuldade em perceber que seja condenado ao Inferno o praticante de uma qualquer religião minoritária. Do mesmo modo que, sem terem em conta os efeitos socialmente negativos que provocava nas suas vítimas, revelam dificuldades em compreender a severa condenação que atinge a alcoviteira Brízida Vaz. Isto para não falar do humilde sapateiro, que apenas parece ter exagerado no dinheiro que cobrava ao povo no desempenho do seu ofício.

Em face das circunstâncias atuais, podem já compreender-se mais facilmente as condenações do onzeneiro e do fidalgo tirano. O primeiro é um ganancioso: praticou a usura, através de empréstimos a juros elevados. Traz consigo o bolsão onde guardava os capitais mas declara que vai vazio. No seu entendimento alienado, bastaria voltar ao mundo e recuperar parte do dinheiro que acumulou em vida, para convencer o Anjo a recebê-lo. O segundo é um fidalgo de solar e, ao invés do que previa o contrato social, revelou-se distante e

\footnotetext{
${ }^{9}$ João Nuno Sales vem, de há muito, chamando a atenção para a importância do substrato iconográfico na dramaturgia vicentina. Veja-se, por exemplo, a excelente síntese que nos fornece sobre o assunto no recente Compêndio de Gil Vicente: "O teatro por imagem".

${ }^{10} \mathrm{~A}$ respeito da representação do Auto da Alma, desde os trabalhos de Braamcamp Freire, vem prevalecendo, com bons fundamentos, a ideia de que ela ocorreu na quinta santa do ano de 1518 (2 de abril) e não em 1508, como se indica na Compilação.
} 
tirano em relação às dificuldades dos pequenos. Também ele julga poder chegar ao Paraíso através da simples invocação do seu estatuto ou de simples orações de sufrágio.

De resto, a alienação constitui uma característica comum a todos os condenados: não compreendem nem aceitam que os valores pelos quais se regeram enquanto vivos não se aplicam no Além. Deste modo, embora possa dizer-se que é essencialmente preenchida por sombras (personagens falecidas), a peça ilustra sobretudo a obstinação de quem não consegue aceitar a mudança da morte e a justiça nova e definitiva que dela resulta.

\section{O sentido de uma moralidade}

A cena que requer mais explicação é, no entanto, a última. É quase impossível não reparar, em primeiro lugar que, antes de ingressarem na Barca do Bem, os cavaleiros de Cristo são interpelados pelo diabo:

Cavaleiros, vós passais

E nam me dizeis pera onde is? (p. 242) ${ }^{11}$

Ao contrário do que sucede com todas as outras personagens (incluindo o Parvo Joane), essa intercepção não resulta em diálogo. A aparente sobranceria dos cavaleiros pode querer dizer que, tal como sucedia com as outras personagens, também eles tinham pecados. Desta vez, contudo, não existe lugar à sua evocação.

Empunhando espadas e escudos (atributos da sua militância cruzadística) as quatro figuras tinham surgido em cena entoando um vilancete de louvor à barca segura, que se inicia com o seguinte mote:

À barca, à barca segura, guardar da barca perdida àbarca, à barca da vida! (p. 241)

Em resposta à tentativa de acusação do Diabo, as personagens que encerram o desfile apressam-se a alegar a sua condição de Mártires de Cristo (testemunhas da Fé), lembrando que o tipo de morte que sofreram basta para os resgatar de todos os pecados que eventualmente pudessem ter cometido:

Morremos nas partes d'além

e não queirais saber mais. (p. 242)

É então a vez de o Anjo assumir um discurso assertivo, aduzindo a causa que explica o acesso imediato dos cavaleiros à Salvação. Recorde-se que, ao longo do auto, a assertividade encontra-se apenas no discurso do Diabo, a quem cabe acusar e explicar.

Desta vez, contudo, os papéis invertem-se. O motivo para esta alteração parece claro: já tínhamos visto o Anjo ser benévolo para com o Parvo, a quem assegurou a Salvação. Mas, se repararmos bem, quando se dirige à personagem, o arrais do Céu tinha anunciado que se encontrava à espera de alguém:

\footnotetext{
11 As citações do texto vicentino são feitas a partir do vol. I das Obras de Gil Vicente, editado pela Imprensa Nacional/Casa da Moeda, em 2001, sob coordenação científica de José Camões.
} 
Tu passarás se quiseres.

Espera entanto per i:

veremos se vem alguém

merecedor de tal bem

que deva d' entrar aqui. (p. 225)

Ora, a chegada dos cavaleiros coincide com a concretização desse anúncio. O motivo do resgate é indicado com clareza, a encerrar o texto da peça:

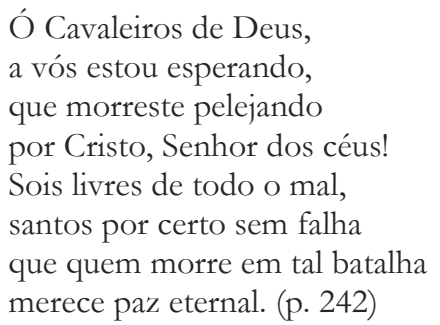

Não vale a pena acalentar ilusões: devolver vida e voz a uma criação teatral de há 500 anos requer algum esforço de compreensão histórica. Mas é necessário fazer esse esforço de alteridade, quer quando lidamos com espetadores quer quando se pensa nos alunos. Depois de vermos a peça e de nela termos pensado, ficamos bem mais preparados para entender os dilemas do Bem e do Mal: aqueles que eram próprios da sociedade quinhentista, em primeiro lugar; mas também (porque não?) aqueles outros que são característicos do nosso tempo.

Para tal, nem sequer precisamos de sair completamente do século XXI. Com os pés assentes no chão que nos coube pisar, apuremos o ouvido para escutar a sensibilidade e a moral de um outro tempo. Descobriremos que, afinal, esse tempo estranho não está ainda tão afastado de nós como à primeira vista pode parecer.

\section{Referências}

Obras de Gil Vicente (coordenação científica de José Camões), Lisboa, Imprensa Nacional/casa da Moeda, 2001 (vol. I).

BERNARDES, José Augusto Cardoso e José Camões (coordenadores), Compêndio de Gil Vicente, Coimbra/Lisboa, Imprensa Nacional/casa da Moeda/Imprensa da Universidade de Coimbra, 2018.

BERNARDES, José Augusto Cardoso, "As Barcas de de Gil Vicente: artes moriendi e horizonte escatológico na corte de D. Manuel”, in Redenção e Escatologia. Estudos de Filosofia, Religião, Literatura e Arte na Cultura Portuguesa, Coordenação de Samuel Dimas, Renato Epifânio e Luís Lóia, Lisboa, Lisboa, Rodapé Edições, 2015, p. 185-198.

CAMÕES, José, "A fortuna editorial da obra de Gil Vicente", in Compêndio de Gil Vicente, p. 123-165.

CORREIA, Amélia, "Gil Vicente no cânone escolar. O(s) texto(s) e a(s) leituras, in Compêndio de Gil Vicente, p. 517-543.

FREIRE, Anselmo Braamcamp, Gil Vicente, trovador mestre da balança, Lisboa, Revista Occidente, 1944 ( $2^{\mathrm{a}}$ edição corrigida).

SALES, João Nuno, "O teatro por imagem", in Compêndio de Gil Vicente, p. 467-493.

TAMAYO-ACOSTA, Juan-José, Para compreender la Escatología Cristiana, Pamplona, Editorial Verbo Divino, 1983.

WALLS, Jerry L., The Oxford Handbook of Eschatology, Oxfor, Oxford University Press, 2008. 